* Este artigo baseia-se em apresentação no Centro de Estudos Estratégicos da Fundação Oswaldo Cruz (Fiocruz) em um dos debates da série: Futuros para o SUS: ideias para a ação, em julho de 2017.
1 Universidade Federal do Rio de Janeiro (UFRJ) - Rio de Janeiro (RJ), Brasil. Orcid: https://orcid. org/0000-0001-87302244

ligiabahia55@gmail.com

2 Universidade de São Paulo (USP) - São Paulo (SP), Brasil.

Orcid: https://orcid org/0000-0001-89316471

mscheffer@uol.com.br

\section{O SUS e o setor privado assistencial: interpretações e fatos*}

\author{
The Unified Health System (SUS) and the private assistance sector: \\ interpretations and facts
}

Ligia Bahia', Mario Scheffer ${ }^{2}$

DOI: 10.1590/0103-11042018S312

RESUMO O ensaio abordou problemas para refletir, identificar contradições e formular estratégias políticas sobre a privatização do sistema de saúde no Brasil, especialmente as próprias acepções sobre o Sistema Único de Saúde (SUS), sobre o que é público e o que é privado. Constatou-se que as relações entre público e privado apreendidas somente por medidas (quantidade de unidades, atividades, recursos humanos e financeiros) estão subjacentes a interesses e negociações entre agentes e suas decisões políticas e a dificuldades para discernir os traços estruturais de um sistema de saúde desigual e segmentado das conjunturas políticas que os reproduzem. Trinta anos após a Constituição de 1988, houve avanços, impasses e retrocessos; assim como adaptações na compreensão do SUS e do setor privado.

PALAVRAS-CHAVE Sistema Único de Saúde. Privatização. Setor privado.

ABSTRACT The essay discusses problems to reflect on, identify contradictions, as well as discern and formulate political strategies on the privatization of the health system in Brazil, especially the multiple meanings of the Unified Health System (SUS) and about what is public and what is private. It is observed that the relations between public and private seized only by measures (quantity of units, activities and human and financial resources) are underlying interests and negotiations between agents and their political decisions and difficulties to discern the structural features of an unequal health system and segmented from the political conjunctures that reproduce them. Thirty years after the 1988 Constitution, there have been advances, impasses and setbacks, as well as adjustments in the understanding of the SUS and the private sector.

KEYWORDS Unified Health System. Privatization. Private sector. 


\section{Introdução}

De um tempo para cá, temos recorrido a figuras de linguagem nas quais o Sistema Único de Saúde (SUS), como sujeito de orações, localiza-se em espaços conflitantes: 'o SUS na encruzilhada', 'o SUS na mira', o 'SUS sob ataque'; e, após a Emenda Constitucional 95, que reduz gastos públicos: 'Desmonte do SUS'. Tais expressões ora alertam para a perda de rumos ou risco iminente de derrota, ora conotam a necessidade de proteger o SUS de desvios dos caminhos e ataques de inimigos. São alusões úteis à aproximação da realidade. Certamente, as políticas sociais (e a saúde não é exceção) estão sendo submetidas a restrições que descaracterizam completamente a acepção original de seguridade social da Constituição de 1988.

No entanto, faltaria sustentação às metáforas sobre o SUS caso o tempo fosse considerado. Governos anteriores também 'atacaram' o SUS. A rigor, a acepção de um SUS como coisa concreta, quase sempre uma rede assistencial pública e vigilância sanitária e epidemiológica, tampouco é aquela aprovada em 1988. Quando se restringe a política de saúde ao que 'acontece com o SUS' (reduzido ao Ministério e Secretárias de Saúde), parte importante dinâmica dos conflitos e interesses setoriais fica oculta. A acepção de um jogo limitado a movimentos declarados de parcela dos agentes públicos dificulta identificar e explicar os processos não lineares que marcaram a trajetória do SUS.

Entre os problemas para refletir, identificar contradições bem como discernir e formular estratégias políticas sobre a privatização do sistema de saúde no Brasil, situam-se as próprias acepções sobre SUS e acerca do que é público e do que é privado. As relações entre público e privado costumam ser apreendidas por medidas (quantidade de unidades, atividades e recursos humanos, financeiros) e, nem sempre, pelas expressões manifestas de interesses e negociações entre agentes e suas decisões políticas. Em meio a tantos números favoráveis ou desfavoráveis ao público, ou ao privado, fica difícil separar os traços estruturais de um sistema de saúde desigual e segmentado das conjunturas políticas que os reproduzem e até os ampliam. Trinta anos após a Constituição de 1988, houve avanços, impasses e retrocessos; assim como adaptações na compreensão do SUS e do setor privado.

Nessa conjuntura, caracterizada pela crise econômica e política e por cortes de recursos para a saúde, torna-se especialmente relevante estabelecer um debate sobre as relações entre a recessão, as políticas de austeridade, a situação de saúde e o SUS. As tarefas para dimensionar possíveis tendências de piora de indicadores e buscar respostas concretas para reduzir riscos sociais, ambientais e individuais e atendimento a problemas de saúde, tais como doenças crônicas, violências, obesidade e arboviroses, são incontornáveis. No entanto, este texto enfoca apenas um dos aspectos do sistema de saúde no Brasil: a segmentação e estratificação assistencial. A intenção - ainda que a relevância dos processos gerais e de longo prazo seja inquestionável - é jogar luzes sobre elementos conjunturais contemporâneos, e, dessa forma, evitar a desatenção para as iniciativas em curso e recursos financeiros e simbólicos concentrados em determinados agentes sociais.

Assim, a equação que orienta a reflexão é a de que os movimentos que afetam a propriedade, finanças e responsabilidade do setor público são causa, e não tão somente consequência de determinantes gerais, de desigualdades impostas por um 'Estado' e sociedade estruturalmente hostis às políticas públicas universais. As práticas efetivas de agentes envolvidos, suas atividades táticas, seus cálculos e especialmente o substrato cognitivo que informa essas ações delimitam objetivamente o âmbito de alternativas políticas. O pressuposto desta breve e necessariamente sintética reflexão é que as estratégias políticas de forças sociais concorrentes com o SUS público e universal foram e 
têm sido recepcionadas sob o registro do SUS para pobres. A hipótese a ser posteriormente analisada é que a sociedade, sempre que perguntada, declarou prioridade para a saúde, apoio ao SUS, ao pagamento de impostos e a alocação de recursos em políticas universais. No entanto, as coalizões governamentais, os governos e determinados dirigentes, diante de restrições fiscais e possivelmente orientados por uma compreensão equivocada sobre saúde, acataram e implementaram políticas de saúde orientadas por recortes focalizados.

Entretanto, a conjectura sobre a cristalização da compreensão do SUS pelas instâncias empresariais e governamentais, como assistência para pobres, será, por enquanto, apenas delineada; obviamente seus contornos e desdobramentos requerem análises específicas, que escapam ao foco do texto. O ponto de partida adotado aqui é que a perspectiva de um sistema público de saúde abrangente e de qualidade ficou de pé. Porém o projeto de SUS efetivamente universal nunca foi e não é consensual, inclusive no segmento que declara o apoiar.

\section{SUS: um conceito polissêmico}

Após a Constituição, o SUS torna-se um termo polissêmico, condensando-se, posteriormente, como rede pública de serviços. A operação de substituição do sistema pelos serviços e do universal por assistência para os pobres, para quem não pode pagar, amputou o conceito ampliado de saúde. Não é por acaso que se passou a considerar o SUS equivalente ao 'sistema suplementar', a utilizar expressões como 'SUS dependente' como se fossem naturais . A acepção de SUS como serviço público para pobres tornou-se, assim, hegemônica. Para uma parte dos políticos, gestores, técnicos e empresários, as tensões e as lutas travadas durante o processo de debates e de aprovação do SUS constitucional em torno da democratização da saúde encontraram um equilíbrio duradouro e virtuoso com a segmentação do sistema. O documento da entidade empresarial Instituto Coalizão Saúde, criada em 2015 e liderada pelo presidente da maior empresa de planos privados de saúde no Brasil, afirma:

Sempre na defesa intransigente do Sistema Único de Saúde. E com a convicção de que, como determina a nossa Constituição, a coexistência e a colaboração entre setores público e privado podem e devem proporcionar um melhor atendimento à nossa população - desde a prevenção e atenção básica até o mais sofisticado recurso que a medicina pode oferecer'1.

Sem definir, portanto, de que SUS estamos falando, surgem realidades supostamente inesperadas ou, ao menos, muito distanciadas daquelas já quase lendárias histórias sobre as disputas sobre o direito à saúde, que antecederam o texto constitucional. Não se menciona o direito à saúde, e, sim, o SUS e a coexistência entre o público e o privado para o ‘atendimento'.

\section{O SUS constitucional e uma trajetória de implementação pragmática}

O SUS constitucional tinha um orçamento compatível com a missão da universalização do direito à saúde. As duas novas fontes de custeio (Contribuição para o Financiamento da Seguridade Social - Cofins e Contribuição Social sobre o Lucro Líquido - CSLL) para a seguridade social somadas às anteriores (impostos gerais e contribuição previdenciária) seriam suficientes para a expansão de direitos sociais. Entretanto, a seguridade social jamais foi implementada. Mal a Constituição foi aprovada, a conversa sobre direitos que não cabem no orçamento se disseminou. Atualmente, predominam ideias errôneas sobre o texto constitucional. As principais interpretações incorretas são: 1) o SUS foi 
promulgado sem o devido financiamento; 2) houve um conchavo dos sanitaristas com setores conservadores em torno da permissão para a atuação da iniciativa privada.

A história, no entanto, é mais interessante do que suas versões estilizadas e está bem documentada. As entidades da sociedade civil se organizaram em torno de arenas de negociação específicas nos debates sobre a Constituição. Na saúde, os sanitaristas estabeleceram acordos com parlamentares progressistas. Além disso, o setor privado buscou apoio no centrão ${ }^{2}$ (parlamentares que representavam setores sociais mais conservadores, maioria na Constituinte, expressaram-se em votações importantes, como a questão da reforma agrária, na qual foi preservada a distribuição desigual da terra). A aprovação do SUS foi uma inequívoca conquista. Sua viabilidade, porém, era reconhecidamente um enorme desafio.

Havia fragilidades amplamente reconhecidas pelos sanitaristas ${ }^{3}$. A origem da proposta de mudança, técnicos e pesquisadores das universidades, implicava a mobilização, convencimento e participação dos trabalhadores e de suas entidades. No final dos anos 1980, trabalhadores especializados já estavam vinculados a esquemas assistenciais privados, e seria imprescindível que apoiassem a destinação das contribuições previdenciárias para um fundo comum e que integrassem as fileiras de combate ao modelo privatizante que se pretendia superar. Analogamente, estava estabelecida a urgência de buscar apoio para o projeto da Reforma Sanitária entre os profissionais de saúde.

O desenrolar dos acontecimentos implicou a revisão de tais expectativas. Mudanças no cenário internacional e a inclinação conservadora do governo Sarney impuseram imensas dificuldades à implementação do SUS. É preciso recordar que os três ministros progressistas da Previdência na Nova República, Waldir Pires (que cunhou a expressão 'a Previdência é viável'), Raphael de Almeida Magalhães e Renato Archer, tiveram mandatos curtos (entre 1985 e 1988) e foram sucedidos por Jader Barbalho. Hesio Cordeiro permaneceu na presidência do Instituto Nacional de Assistência Médica da Previdência Social (Inamps) entre 1985 e 1988 e foi substituído por um médico, que havia participado da gestão de Jarbas Passarinho, conterrâneo e ligado à família presidencial.

Já em 1989, o documento 'Adult Health in Brazil: adjusting to new challanges', do Banco Mundial ${ }^{4}$, afirmava que seria impossível financiar com recursos públicos a saúde para todos, avançando propostas sobre a configuração público-privada mais adequada para o Brasil: os pobres teriam melhores serviços de saúde se o "setor público imitasse o setor industrial brasileiro moderno contratando serviços das empresas de planos de saúde"4(48). Collor de Mello, cujo mandato iniciou em 1990, seguiu os preceitos do tripé: desestatização, desregulamentação e liberalização de preços e salários. Seu discurso de posse explicitou sua concepção sobre a natureza assistencialista das políticas sociais:

O Estado deve ser apto, permanentemente apto a garantir o acesso das pessoas de baixa renda a determinados bens vitais. Deve prover o acesso à moradia, à alimentação, à saúde, à educação e ao transporte coletivo a quantos dele dependam $[. . .]^{5}$.

Após a Constituição, o projeto de efetivar um SUS universal foi dramaticamente restringido pela redução dos recursos para a saúde (para patamares menores do que as despesas em 1987). Como o SUS, especialmente, o financiamento para as ações da rede pública de saúde encontrou apoiadores no movimento municipalista. Consequentemente, a ação política desse movimento ampliou as bases políticas do SUS, contudo, o protagonismo de prefeitos e secretários de saúde acompanhou-se pela ênfase nas dimensões administrativo-institucionais da rede de serviços. O subfinanciamento, o teor eminentemente contencionista 
e descentralizador da implementação do SUS, conduzida por gestores ${ }^{6}$, bem como a retomada das posições relevantes de influência de hospitais privados aliados a empresas de planos de saúde no Congresso Nacional e ao Poder Executivo resultaram em esforços notáveis para a ampliação do acesso. Tais iniciativas, porém, não se direcionaram à compreensão e à tradução operacional do conceito ampliado de saúde. O Brasil é o único país da América do Sul que possui um sistema universal de saúde. No entanto, não é a nação do continente que gasta mais recursos com saúde pública. Existe uma contradição estrutural: apesar do sistema universal, os gastos com saúde são menores do que os de países vizinhos, e as despesas privadas são maiores do que as públicas ${ }^{7}$.

\section{SUS: magnitude da oferta e acesso}

Entre 2003 e 2013, houve uma significativa ampliação do acesso da população a cuidados de saúde: a proporção de pessoas que se consultaram com médicos aumentou de 54,7\% em 1998 para 71,2\% em 20138. Em 2014, mais de $90 \%$ dos que se declararam ser hipertensos ou diabéticos e $88 \%$ dos portadores de doença pulmonar obstrutiva crônica obtiveram os remédios prescritos ${ }^{9}$. As estratégias para expansão de coberturas, especialmente investimentos na atenção básica, foram positivas. O número de equipes de saúde da família aumentou de 4.114 em 1999 para 54.205 em 2017. Neste mesmo ano, as equipes estavam localizadas em $4.995 \mathrm{mu}-$ nicípios, sendo potencialmente responsáveis pela cobertura de cerca de 127 milhões de pessoas ${ }^{10}$. Existem evidências sobre a atenção propiciada pelas equipes de saúde da família e a redução na taxa de mortalidade infantil pós-neonatal (amplamente atribuível à redução no número de mortes por doença diarreica e por infecções do aparelho respiratório) ${ }^{11}$ e ainda diminuição de internações hospitalares potencialmente evitáveis $^{12}$. Além de ações ambulatoriais básicas, o SUS realiza, entre outras atividades, transplantes e fornece medicamentos caros para as pessoas vivendo com HIV/Aids e portadores de doenças raras.

A oferta de leitos hospitalares da rede de serviços do SUS é abrangente e diversificada, inclusive para pediatria, obstetrícia e oncologia. No entanto, o acesso e o uso de determinados serviços especializados pela rede SUS são racionados, em função da existência de tetos orçamentários e de uma oferta, constituída majoritariamente por prestadores privados, que só atendem a clientelas dos planos de saúde. Por exemplo: a oferta pública (privada contratada) predominou na terapia renal substitutiva (considerando estabelecimentos cadastrados e que podem ser identificados pela especialidade) em 2016. No entanto, os estabelecimentos de radioterapia registrados estão voltados às demandas privadas.

Tabela 1. Estabelecimentos de saúde selecionados segundo procedimento no Cadastro Nacional de Estabelecimentos de Saúde (CNES), Brasil, 2017

\begin{tabular}{lrrrrrr}
\hline Procedimento & Privada & Pública & Filantrópica & Total & SUS & $\%$ \\
\hline Hemodiálise & 102 & 4 & 0 & 106 & 80 & 75,47 \\
Radioterapia & 81 & 0 & 5 & 86 & 20 & 23,26 \\
\hline
\end{tabular}

Fonte: Elaboração própria, baseada em dados do Datasus ${ }^{\mathbf{1 3}}$ 
Algumas especialidades, como, por exemplo, o atendimento para queimados em hospitais e transplantes, são praticamente exclusividade da rede SUS. Contudo, a oferta de leitos cirúrgicos para especialidades estratégicas, como oftalmologia, gastroenterologia e otorrinolaringologia, é eminentemente direcionada ao atendimento de clientelas privadas (tabela 2).

Tabela 2. Número de leitos (SUS e planos privados) segundo especialidades selecionadas, Brasil, 2018

\begin{tabular}{lrrrr}
\hline Especialidades & SUS & Não SUS & Total & \% SUS \\
\hline Queimado Adulto & 189 & 17 & 206 & 91,75 \\
Pediátricos & 39657 & 10926 & 50583 & 78,40 \\
Obstétricos & 39746 & 13503 & 53249 & 74,64 \\
Neurocirurgia & 3617 & 1420 & 5037 & 71,81 \\
Oncologia & 4105 & 2034 & 6139 & 66,87 \\
Cirurgia geral & 37684 & 22240 & 59924 & 62,89 \\
Ginecologia cirúrgica & 4338 & 2674 & 7012 & 61,87 \\
Cardiologia cirúrgica & 3083 & 2304 & 5387 & 57,23 \\
Oftalmologia & 1169 & 1444 & 2613 & 44,74 \\
Gastroenterologia & 913 & 1150 & 2063 & 44,26 \\
Otorrinolaringologia & 795 & 1341 & 2136 & 37,22 \\
\hline Fonte Eloboraça propia
\end{tabular}

Fonte: Elaboração própria, baseada em dados do Datasus ${ }^{\mathbf{1 3}}$.

Observa-se ainda insuficiência e proporção declinante para a demanda pública de equipamentos de tomografia computadorizada $(47,8 \%$ em 2008 e 43,3\% em 2018) exposta no gráfico 1. Paradoxalmente, $30 \%$ de clientes de planos de saúde possuem acesso potencial a $60 \%$ de equipamentos para exames de imagem de maior custo. A oferta de leitos de Centro de Tratamento Intensivo (CTI) também é desequilibrada e manteve-se relativamente estável, especialmente entre 2014 e 2018 (gráfico 2).

Essa 'especialização' da rede SUS não admite interpretações simplificadas; e o termo 'complexidade' e os adjetivos alta e média frequentemente não contribuem para o desvelamento dos enclaves corporativistas e empresariais subjacentes às lacunas e distribuição da oferta pública. Houve ampliação do acesso a determinadas ações ambulatoriais e hospitalares, mas não para todas. Simultaneamente, observa-se o predomínio da oferta da rede SUS em especialidades associadas à realização de procedimentos caros, mas também não para todas. Consequentemente, o gargalo do SUS não é, como se diz por aí, a 'alta e média complexidade', e, sim, as políticas de divisão público-privada de procedimentos, ações e valores de remuneração orientada por interesses particulares. 
Gráfico1. Número de equipamentos de tomografia (planos privados, SUS e \% SUS), Brasil 2008 a 2018

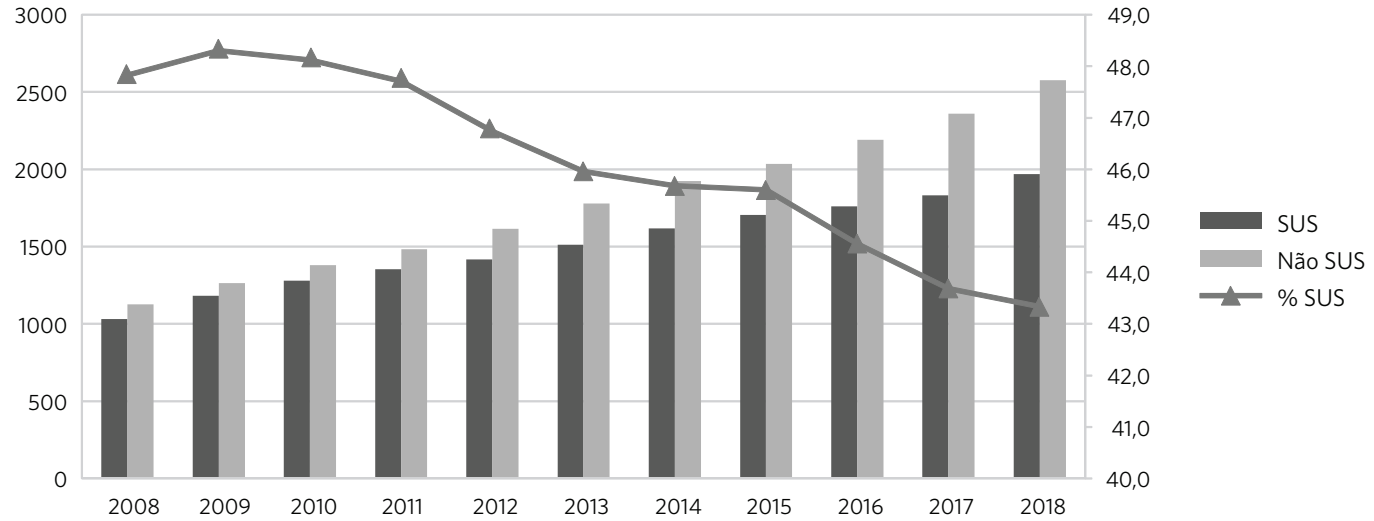

Fonte: CNES ${ }^{14}$

Gráfico 2. Leitos de CTI (planos privados, SUS e \% SUS), Brasil 2008 a 2018

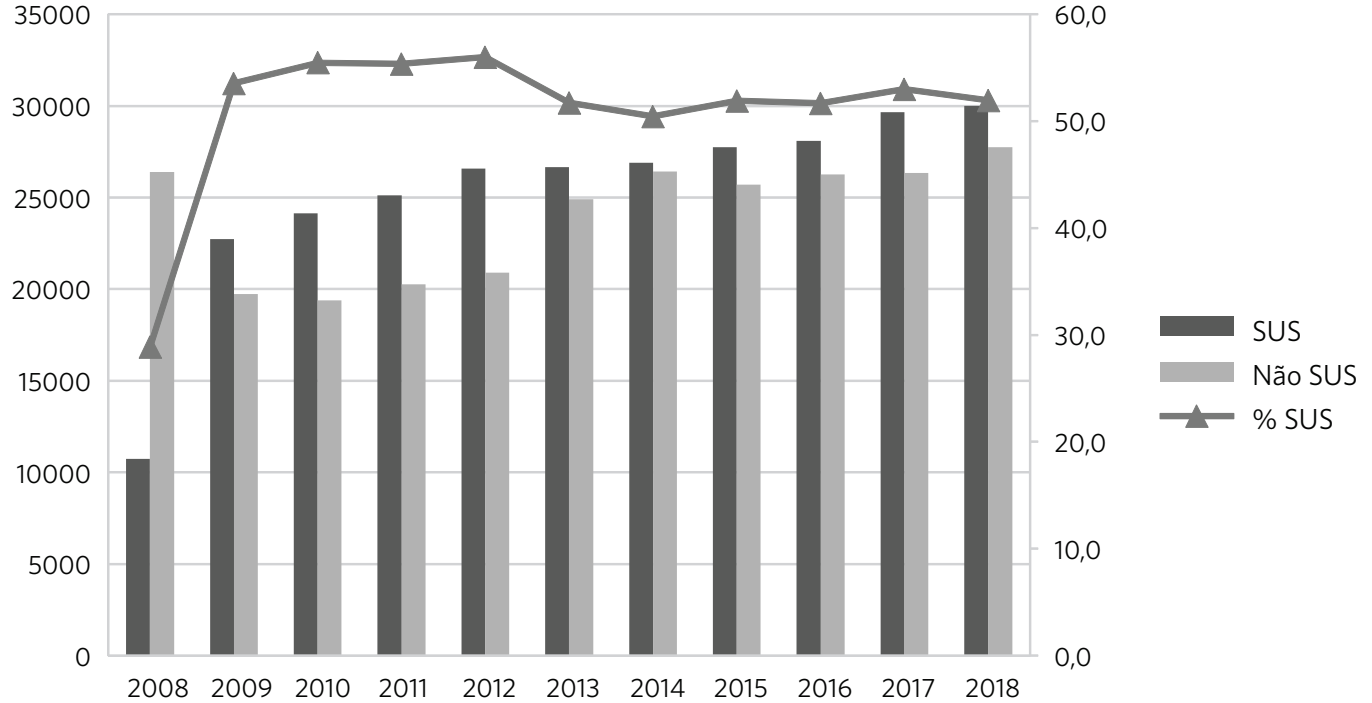

Fonte: CNES14

\section{Expansão das bases financeiras e políticas do setor privado assistencial}

Definições e dimensionamentos equivocados sobre o setor privado, especialmente quando mobilizados para afirmar o público contraposto ao mercado, também contribuem para a apreensão difusa do termo SUS. Não são poucos os gestores, técnicos e agora até mesmo sanitaristas que se valem da dicotomia SUS e 'saúde suplementar' para explicar o sistema de saúde no Brasil. Consequentemente, não são poucas as explicações sobre os problemas da saúde baseadas 
na existência de dois subsistemas que, por sua vez, hiperinflacionaram a difusão de proposições de articulação e integração entre o público e o privado. Essas acepções seriam inócuas se não fosse o fato de elas embasarem a falsa suposição de que existe um equilíbrio, que as proporções entre a demanda 'pagante' correspondem à oferta disponível e às despesas. Na realidade, a oferta e as despesas para o SUS são menores do que as demandas. Inversamente, a oferta e as despesas do setor privado assumem proporções maiores do que as demandas. Ou seja, o senso comum sobre mercados do tamanho dos bolsos dos indivíduos e seu desdobramento relativo à virtude do privado para 'desonerar' o SUS não resistem às evidências.

O Brasil possui o segundo maior mercado de planos privados de saúde do mundo. Porém, o tamanho e o peso do 'mercado e público' dependem de métricas que, se usadas a gosto do freguês, poderão sugerir ora o predomínio do público, ora o do privado, sem que se responda à necessidade de identificar e de explicar os fluxos público-privados e acumulação de recursos financeiros e políticos. Uma análise mais realista permite observar a existência de um nexo causal entre políticas públicas das coalizões nucleadas pelo Partido da Social Democracia Brasileira (PSDB) e Partido dos Trabalhadores (PT) à expansão do setor privado. Foram muitas as iniciativas mobilizadas para alavancar o mercado de planos privados de saúde. $\mathrm{O}$ quadro 1 relaciona alguns dos incentivos estratégicos à oferta e demanda.

Quadro 1. Legislação selecionada* relacionada com o apoio à oferta e demanda de serviços e planos e seguros privados de saúde no período pósConstituição de 1988

\begin{tabular}{|c|c|c|}
\hline Governo & Incentivos à Oferta & Incentivos à Demanda \\
\hline Sarney & & $\begin{array}{l}\text { Decreto-Lei no } 7.713 \text {, de } 1988 \text { (amplia os limites } \\
\text { do abatimento do imposto de renda com des- } \\
\text { pesas com saúde) }\end{array}$ \\
\hline Collor/Itamar & $\begin{array}{l}\text { Lei no } 8620 \text {, de } 5 \text { de janeiro de 1993, (desconto e parcelamento de débitos de } \\
\text { hospitais contratados ou conveniados com o Instituto Nacional Inamps) }\end{array}$ & \\
\hline $\mathrm{FHC}$ & $\begin{array}{l}\text { - BNDES Apoio a investimentos na rede privada de serviços médico-hospitalares } \\
\text { (hospitais e unidades de diagnóstico) } \\
\text { - BNDES Modernização de hospitais filantrópicos e estratégicos para o SUS (com } \\
\text { participação da Caixa Econômica Federal) } \\
\text { - Decretos no } 3.504 \text {, de 2000, no -4.499, de 2002, no 4.327, de } 2002 \text { e no 4.588, } \\
\text { de } 2002 \text { (alteração da Lei no 8.212, de 1991, flexibilização dos parâmetros para a } \\
\text { concessão do certificado de filantropia; introduz alternativas: ou 60\% das interna- } \\
\text { ções para o SUS, ou aplicação de parte da receita bruta em gratuidade ou classifi- } \\
\text { cação do hospital como estratégico para o SUS). } \\
\text { - Decreto no } 4.481 \text {, de } 2002 \text { (redução da prestação de serviços dos sistemas de } \\
\text { alta complexidade das entidades filantrópicas destinados ao atendimento univer- } \\
\text { sal para 20\%) } \\
\text { - Medida Provisória no 2.158-35, de } 2001 \text { (deduccões da base de cálculo das des- } \\
\text { pesas operacionais e reservas técnicas das contribuições sociais para empresas } \\
\text { de planos de saúde) }\end{array}$ & $\begin{array}{l}\text { Lei no 9.250, de } 1995 \text { (as despesas com saúde } \\
\text { passam a ser objeto de dedução integral do } \\
\text { imposto de renda) } \\
\text { Lei no } 9.527 \text {, de } 1997 \text { (altera o artigo } 230 \text { da Lei } \\
\text { no 8.122, de } 1990 \text { - Regime Jurídico Único ao in- } \\
\text { troduzir a possibilidade de a assistência à saúde } \\
\text { do servidor ser realizada mediante contrato) } \\
\text { Decreto no 3.000, de } 1999 \text { (atualiza os artigos } \\
17 \text { e } 18 \text { da Lei no } 4.506 \text {, de 1964, que tratam } \\
\text { da isenção do cálculo do rendimento bruto os } \\
\text { serviços médicos, pagos, ressarcidos ou man- } \\
\text { tidos pelo empregador em beneficio de seus } \\
\text { empregados) }\end{array}$ \\
\hline Lula & $\begin{array}{l}\text { - BNDES Apoio a investimentos na rede privada de serviços médico-hospitalares } \\
\text { hospitais, 'leitos não SUS' e unidades de diagnóstico } \\
\text { - BNDES Modernização de hospitais filantrópicos e estratégicos para o SUS } \\
\text { - Instrução Normativa da Secretaria da Receita Federal no 480, de } 2004 \text { (promul- } \\
\text { ga a separação das contas dos serviços de terceiros - entre os quais os médicos } \\
\text { e autoriza a dedução de impostos e contribuições sociais para profissionais de } \\
\text { cooperativas e associações médicas) }\end{array}$ & $\begin{array}{l}\text { Lei no } 11.302 \text {, de } 2006 \text { (altera o artigo } 230 \text { da } \\
\text { Lei no } 8.122 \text {, de } 1990 \text { - Regime Jurídico Único } \\
\text { ao introduzir a possibilidade de assistência ao } \\
\text { servidor mediante a forma de auxílio - ressarci- } \\
\text { mento do valor parcial dos gastos com planos } \\
\text { ou seguros privados de assistência à saúde) }\end{array}$ \\
\hline
\end{tabular}


Quadro 1. (cont.)

\begin{tabular}{|c|c|c|}
\hline Lula & $\begin{array}{l}\text { - Decreto no 5.895, de } 2006 \text { (introdução de novos critérios para a concessão do } \\
\text { certificado de filantropia: oferta de serviços no percentual mínimo de } 60 \% \text { ou } \\
\text { realização de projetos de apoio ao desenvolvimento institucional do SUS nas se- } \\
\text { guintes áreas de atuação: 1) estudos de avaliação e incorporação de tecnologias; } \\
\text { 2) capacitação de recursos humanos; 3) pesquisas de interesse público em saúde; } \\
\text { 4) desenvolvimento de técnicas e operação de gestão em serviços de saúde) } \\
\text { - Lei no 11.345, de 2006, e Decreto no } 6.187 \text {, de } 2007 \text { (criação de fonte de re- } \\
\text { cursos -Timemania - parte da arrecadação é enviada para o Fundo Nacional de } \\
\text { Saúde e destinada a Santas Casas, entidades hospitalares sem fins econômicos e } \\
\text { entidades de reabilitação de portadores de deficiência e parcelamento de débitos } \\
\text { tributários) } \\
\text { - Lei no } 10.833 \text {, de } 2004 \text { (preservação do regime de redução da alíquota da Con- } \\
\text { tribuição de para Financiamento da Seguridade Social (Cofins) de 7,6\% para 3\% } \\
\text { para estabelecimentos privados de saúde) } \\
\text { - Resoluções ANS no } 195 \text { e no } 196 \text { de } 2009 \text {, permite a comercialização de planos } \\
\text { de saúde por coletivos por adesão (ampliação das vendas de contratos que 'esca- } \\
\text { pam' das regras de reajuste e rescisão) e admite a intermediação de administra- } \\
\text { doras nas relações entre clientes e empresas de planos }\end{array}$ & \\
\hline Dilma & $\begin{array}{l}\text { - BNDES Apoio a investimentos na rede privada de serviços médico-hospitalares } \\
\text { hospitais, 'leitos não SUS' e unidades de diagnóstico } \\
\text { - BNDES Reestruturação das dívidas bancárias e com fornecedores das Santas } \\
\text { Casas e entidades filantrópicas } \\
\text { - BNDES empréstimos para empresas de planos privados de saúde } \\
\text { - Lei no13.097, de 2105, novas e amplas exceções à vedação constitucional à par- } \\
\text { ticipação direta ou indireta de empresas ou capitais estrangeiros nas atividades de } \\
\text { assistência à saúde, inclusive hospitais filantrópicos } \\
\text { - Resolução Normativa ANS no 396, janeiro de } 2016 \text { desconto nas multas de } \\
\text { empresas de planos de saúde }\end{array}$ & $\begin{array}{l}\text { Resolução Receita Federal RFB no 1.500/2014 } \\
\text { Dedução do imposto de renda de cirurgias } \\
\text { plásticas estéticas e despesas com saúde no } \\
\text { exterior }\end{array}$ \\
\hline
\end{tabular}

Fonte: Sicon ${ }^{15}$, Sijut16, BNDES17.

* Levantamento incompleto e não sistemático.

Os estímulos governamentais ao setor privado especializado na comercialização de planos e seguros de saúde associados ao aumento da formalização dos empregos e renda contribuíram para a expansão do mercado e aprofundamento da fragmentação e segmentação do sistema de saúde. Observa-se no gráfico 3 que o crescimento das receitas das empresas de planos de saúde (com valores corrigidos), no período de 2001 a 2016, foi significativamente superior ao Produto Interno Bruto (PIB), à inflação; e manteve-se estável mesmo quando houve queda do número de clientes. O descolamento das receitas da base concreta de clientes tem sido considerado um sinal de inserção de grupos econômicos do setor de planos e seguros no regime de dominância financeira. 
Gráfico 3. Variação do número de clientes, receitas de empresas de planos (corrigidas IPCA 2016), PIB real e inflação, Brasil, 2001 a 2016

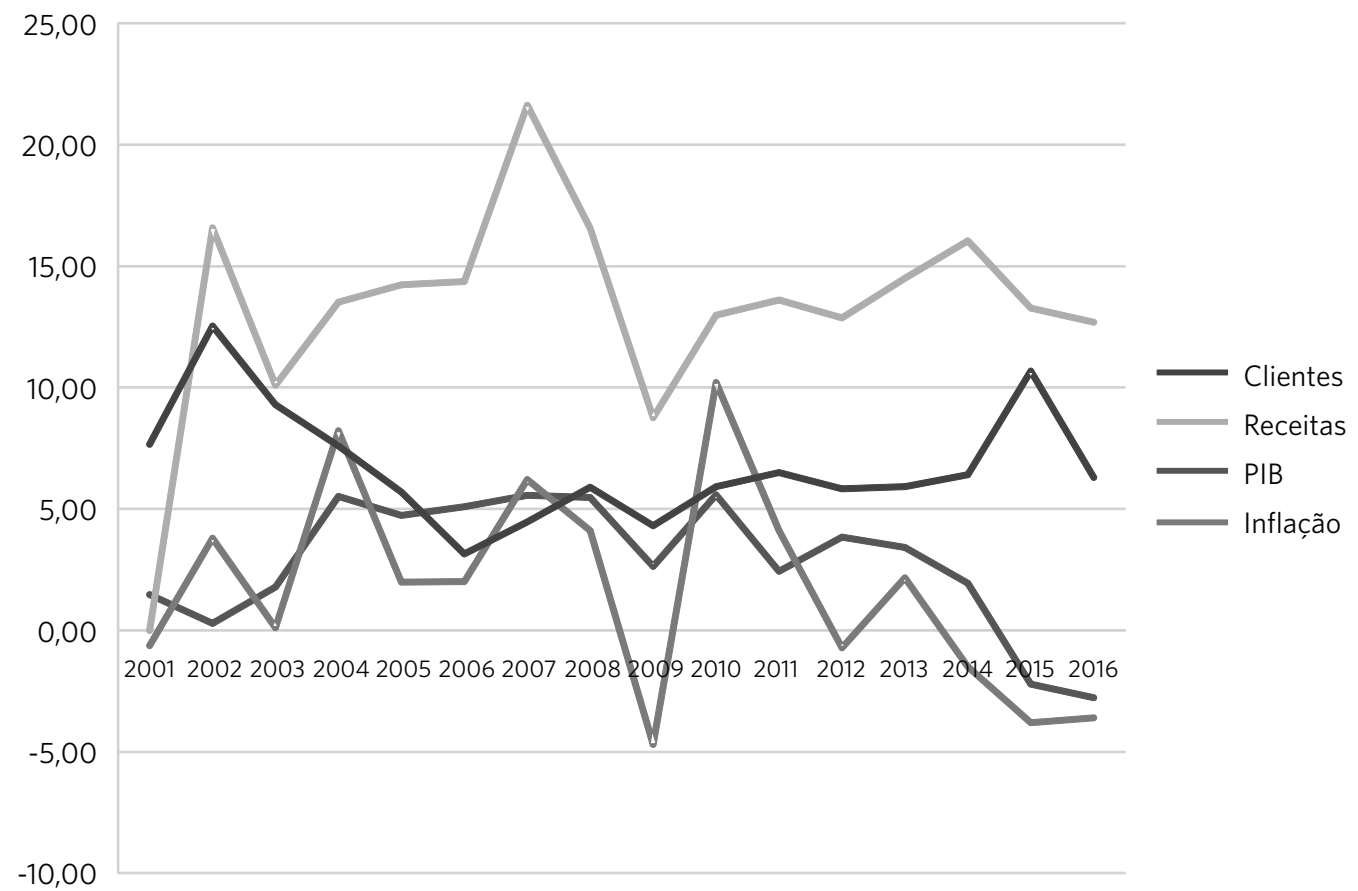

Fonte: Ipeadata ${ }^{\mathbf{1 8}}, \mathrm{ANS}^{\mathbf{1 9}}$, Banco Centra|20

Assim, as repercussões da magnitude do volume de recursos financeiros mobilizada pelas empresas de planos e seguros não se restringem às dimensões econômicas, a financeirização implica atuação ativa de grupos de interesse na definição das políticas públicas.

\section{O fio da meada}

Parcela significativa de profissionais de saúde e entidades da sociedade civil que apoiaram os governos do PT adotou um discurso defensivo sobre os obstáculos ao SUS. Por vezes, recorre-se a metáforas sobre o SUS e a democracia no Brasil, associando-os à infância ou à adolescência, remetendo-os, em termos temporais, à Constituição de 1988, mas também às dificuldades de crescimento, como se não tivessem se tornado 'adultos'. Em outras ocasiões, recorre-se à luta de Davi (os aguerridos sanitaristas) contra Golias (os capitalistas que atuam no setor). Porém, tanto a versão que se apoia na dimensão temporal quanto a que embute uma avaliação de correlação ficcional de forças deixam de lado o papel dos governos e do debate político.

Ainda que o potencial explicativo de analogias entre projetos e construções sociais com ciclos biológicos de vida ou em uma estrutura imutável seja baixo, as equivalências são tentadoras e absolvem. Além disso, enaltecem o passado de árduas lutas por direitos sociais. $\mathrm{E}$ se não for relevante compreender o presente, as afirmações sobre a existência de um processo de conquistas ainda imaturo, em construção, dão bem para o gasto. Abstrair o presente facilita emitir avaliações otimistas ou pessimistas, mais afeitas às profecias sobre o destino inexoravelmente grandioso de um país de riquezas 
mis ou de uma nação sempre fadada ao fracasso. Retomar a ambiguidade do termo Estado, como regulador que assegura a reprodução e acumulação e enquanto detentor de instituições estatais ativas e autônomas que deveriam transcender interesses parciais de grupos específicos e se organizarem em torno de objetivos gerais, poderá contribuir para reencontrar o fio da meada. Nesse sentido, as sugestões convergem em torno do fortalecimento das instituições públicas, das suas burocracias e da geração de atividades voltadas às políticas universais, ou seja, do fechamento de canais de ações governamentais de suporte à privatização.

Com o passar do tempo, diversas interpretações sobre a 'história' do SUS ganharam status de 'verdade'. Entre as inúmeras versões que circulam, especialmente no movimento social, situam-se duas antagônicas: uma delas atribui o SUS a um processo de conquista dos movimentos sociais, uma articulação 'por baixo'; a outra, a um processo de negociação nos debates durante a Constituição de 1988. Como a principal força política que formulou o SUS, o antigo Partido Comunista Brasileiro (PCB), perdeu potência social até mesmo para resgatar seus acertos e erros nas lutas pela redemocratização, a tendência entre os militantes de esquerda, que não participaram diretamente das lutas pela legitimação do direito à saúde, é a de adotarem, mesmo que por vezes de forma pouco clara, a versão do 'conchavo'.

Contudo, a ideia de que houve um 'toma lá dá cá protagonizado por sanitaristas que propunham uma reforma radical obscurece dois fenômenos relevantes à análise das condições concretas das disputas políticas na saúde. $\mathrm{O}$ primeiro é a correlação de forças setoriais. $\mathrm{O}$ SUS foi apoiado pelos parlamentares 'anti-centrão' e certamente galvanizou apoios de setores progressistas do então Movimento Democrático Brasileiro (MDB) em função das repetidas crises do setor privado, naquele momento acusado de fraudes e inimigo de uma saúde digna. O segundo feixe de circunstâncias refere-se à atuação dos sanitaristas tanto por dentro dos fóruns do movimento social quanto no âmbito do Poder Legislativo. A maturação de um projeto de Reforma Sanitária envolveu esforços teóricos e gerou novas formas de inserção de instituições de ensino e pesquisa na vida política do País, sendo que a mais notável foi a convocação de uma conferência de saúde com participação popular em 1986.

Havia divergências entre o PT e o então PCB em torno da 'estatização', tensão que, por sua vez, tinha como substrato a compreensão sobre o processo de ruptura com o capitalismo. Para uns, o núcleo das transformações da Reforma Sanitária consistia na necessidade de travar a batalha por consciência da determinação social sobre o processo saúde-doença. Assim, tratava-se de 'gramscianamente' realizar mudanças radicais na consciência e nas práticas. Para outros, a concepção de reforma e não ruptura parecia inadequada às condições concretas de um País com inserção periférica. Em termos práticos, uma das vias propostas para a reforma, a via congressual, a Assembleia Nacional Constituinte, afigurava-se como uma alternativa 'por cima'.

Tais polêmicas merecedoras de maior aprofundamento parecem, no entanto, ter ficado em um passado remoto. Durante o processo de implementação do SUS, a proximidade com o chamado 'centrão' das coalizões governamentais atravessou barreiras setoriais. Talvez, ainda que com as devidas desculpas pela simplificação, possa-se admitir como hipótese que, após a derrota das forças conversadoras e privatizantes na saúde no processo de debates da Constituição, houve uma reacomodação das forças políticas pró-privatização dinamizadas pela presença de técnicos do movimento sanitário em destacados cargos de gestão do SUS e pela permanente articulação 'por fora', especialmente nos ministérios da área econômica, partidos políticos e Congresso Nacional.

\section{Considerações finais}

A presença ativa de empresários da saúde e de seus representantes em partidos e coalizões 
políticas que governam o País não é vista com maus olhos. Pelo contrário, o atendimento de políticos de diversas origens e vinculações partidárias em hospitais particulares paulistas e a presença em festas de proprietários bilionários de negócios setoriais foram registrados em colunas sociais. Tal exibição de intimidade parece expressar ora admiração pelo empreender bem-sucedido misturada com o assentimento ou resignação com um sistema de saúde clivado pelo atendimento a pobres e a ricos, ora preconceitos e incompreensão sobre os sistemas universais. Partidos e lideranças políticas terminam por corroborar o senso comum sobre a capacidade de estratégias individualizadas responderem a problemas de saúde que são coletivos. Consequentemente, no âmbito da política, também prevalece o ideário sobre a eficiência do privado em relação ao público, bem como a inversão das relações causais, segundo a qual os sistemas universais seriam determinados pela igualdade social e, portanto, não se constituem como vetor de redução de desigualdades.

No âmbito técnico-burocrático setorial, também se observa que a compreensão do SUS como atenção básica para pobres foi incorporada, inclusive nos textos legais, como portarias do Ministério da Saúde, que passam a localizar ações focalizadas, como o Programa Rede Cegonha, entre outras nos 'municípios do Programa Brasil sem Miséria'. A universalização (igualdade) também deixou de parametrizar as políticas de regulação do acesso entre clientes de planos e as demais pessoas pela iniciativa da Agência Nacional de Saúde Suplementar (ANS) de incluir a obrigatoriedade de cobertura de medicamentos antineoplásicos orais. A partir de 2013, a relação dos medicamentos para clientes de planos passou a ser mais ampla do que a recomendada para o SUS. Duas políticas públicas explicitamente diferenciadas segundo capacidade direta ou indireta de pagamento e não critérios clínicos. Em outras instâncias da burocracia pública, vigora o completo desrespeito à relevância pública das ações de saúde. Por exemplo, o Conselho de Defesa da Concorrência (Cade) aprova a aquisição de empresas por grupos que vendem serviços para secretárias estaduais e municipais de saúde.

A atuação dos empresários da saúde, antes predominantemente articulada em torno de agendas bastante particularizadas, foi substancialmente modificada. A criação da entidade Instituto Coalizão Saúde (Icos), no contexto das eleições para a presidência da república de 2014, representou um marco na articulação de grupos econômicos das indústrias (equipamentos, medicamentos) com aqueles que atuam precipuamente na assistência médico-hospitalar. A explicitação da liderança de São Paulo (a entidade é coordenada pelo ex-superintendente do hospital Albert Einstein, atual presidente da maior empresa de planos de saúde e por um professor da Universidade de São Paulo - USP ex-secretário de saúde da cidade de São Paulo) afirma inequivocamente a localização no Sudeste para a 'medicina de qualidade' no País.

As centrais sindicais de trabalhadores apoiaram e apoiam o SUS, mas suas bases demandam planos privados de saúde. Não é raro que um sindicalista pronuncie que os planos privados são benéficos ao SUS, por diminuírem a fila nas instituições públicas. Há aqueles que inclusive individualizam o raciocínio ao dizer: "assim deixo meu lugar na fila para alguém pobre". Embora os conflitos entre o empregador que paga, em parte ou totalmente, o plano privado e as demissões por doença do titular ou de seus familiares existam, o assunto não adquire visibilidade.

Os conselhos de saúde tampouco se dedicam ao debate sobre a privatização realizada pelos grandes grupos econômicos. Os representantes das entidades sindicais de profissionais de saúde que os integram tendem a valorizar as demandas trabalhistas decorrentes da contratação precarizada de servidores. Os processos aquisição-fusão, abertura e valorização de capitais, preços de monopólio e presença dos representantes empresariais nos núcleos decisórios governamentais são pouco ou nada debatidos pelas entidades de participação social. 
$\mathrm{O}$ enfrentamento da privatização requer a produção de conhecimentos aprofundados e atualizados sobre o setor privado da saúde. Os esforços para a compreensão dos processos recentes de inserção do setor no padrão de dominância financeira e seus desdobramentos econômicos, sociais, culturais e políticos são incipientes. É preciso priorizar a temática 'grandes grupos econômicos na saúde' e desenvolver estudos específicos sobre as inter-relações entre público e privado sobre os fluxos de acumulação de capital e poder. A recusa peremptória de generalizações - do tipo: o problema é o velho patrimonialismo - é essencial para a definição de perguntas de pesquisa.

As forças progressistas que atuam na saúde não podem continuar ignorando ou consentindo passivamente com a privatização da saúde. Encontrar um espaço de intervenção para a desprivatização requer reconhecer que as articulações entre o público e o privado se estendem desde a atuação de profissionais de saúde em ambos os setores até no uso de fundos públicos e privados nacionais e internacionais. No entanto, os processos em curso que viabilizam a criação de novos mercados não têm sido detectados. Políticas de privatização recentes foram implementadas praticamente sem oposição parlamentar e dos movimentos sociais. Mesmo quando foi possível antepor barreiras a ações privatizantes, como no caso da anistia às multas das empresas de planos de saúde, os lobbies privados lograram encontrar uma alternativa administrativa para aprovar seu pleito.

Consequentemente, é necessário debater com técnicos dos ministérios da área econômica, da justiça, bem como com o Ministério Público e Poder Judiciário, os problemas da saúde e do sistema de saúde para apresentar e testar alternativas de redução do uso do fundo público para a privatização. São gritantes contradições as deduções e isenções fiscais, os estabelecimentos filantrópicos-privados, o pagamento de planos muito caros para servidores públicos, o pagamento de taxas elevadas de administração para terceirizações e a corrupção. As portas giratórias precisam ser identificadas e, quando possível, controladas ou fechadas. Não se trata de criminalizar e de denunciar conflitos de interesses mas de constatar que a influência do setor privado na saúde é muito extensa e intensa.

\section{Colaboradores}

Bahia L e Scheffer M contribuíram para o planejamento, análise, revisão crítica do conteúdo e aprovação da versão final do manuscrito.

\section{Referências}

1. Instituto Coalizão Saúde. Coalizão Saúde Brasil: uma agenda para transformar o sistema de saúde [internet]. São Paulo: Icos; 2016 [acesso em 2018 out 12]. Disponível em: http://icos.org.br/wp-content/uploads/2017/04/ Relato\%CC\%81rioNet.pdf.
2. Carvalho LM. 1988: segredos da constituinte. Rio de Janeiro: Record; 2017

3. Rodriguez-Neto E. Saúde: promessas e limites da Constituição. Rio de Janeiro: Fiocruz; 2003. 
4. World Bank. Adult Health in Brazil: adjusting to new challenges [internet]. Washington: World Bank; 1989 [acesso em 2018 out 12]. Disponível em: http://documents.worldbank.org/curated/en/578971468016251145/ pdf/multiopage.pdf.

5. Brasil. Presidência da República. O projeto de reconstrução nacional [internet]. Brasília, DF: Biblioteca Presidência da República; 1990. Disponível em: http://www. biblioteca.presidencia.gov.br/presidencia/ex-presidentes/fernando-collor/discursos/discurso-de-posse/posse-collor.pdf/view.

6. Paim J. Reforma sanitária brasileira: contribuição para a compreensão e crítica. Salvador: Edufba; Rio de Janeiro: Fiocruz; 2008.

7. Luzuriaga MJ, Bahia L. Procesos de expansión y límites a la privatización de la atención de la salud en América Latina: más allá de las tipologías. Cad Saúde Pública. 2017; 33(sup.2):1-12.

8. Instituto Brasileiro de Geografia e Estatística. Pesquisa Nacional de Saúde. Rio de Janeiro: IBGE; 2013.

9. Bermudez JAZ, Barros MBA. Perfil do acesso e da utilização de medicamentos da população brasileira - contribuições e desafios da PNAUM - Inquérito Domiciliar. Rev Saúde Pública. 2016; 50(supl.2):1-4.

10. Brasil. Ministério da Saúde. Secretaria de Atenção. Sistema de Informação da Atenção Básica. Brasília, DF: MS; 2018.

11. Macinko J, Guanais FC, Souza MF. Evaluation of the impact of Family Health Program on infant mortality in Brazil, 1990-2002. J Epidemiol Community Health. 2006; 60(1):13-19.

12. Pinto LF, Giovanella L. Do Programa à Estratégia Saúde da Família: expansão do acesso e redução das interna- ções por condições sensíveis à atenção básica (ICSAB).

Ciênc Saúde Colet. 2018; 23(6):1903-1914.

13. Brasil. Ministério da Saúde. Sistema Único de Saúde. Datasus [internet]. Brasília, DF: MS; 2017 [acesso em 2018 out 12]. Disponível em: http://datasus.saude.gov.br/.

14. Brasil. Ministério da Saúde. Cadastro Nacional de Estabelecimentos de Saúde. Brasília, DF: MS; 2017 [acesso em 2018 out 12]. Disponível em: http://cnes.datasus. gov.br/.

15. Brasil. Sistema de Informações do Congresso Nacional. Brasília, DF: Sicon; 2018 [acesso em 2018 out 12]. Disponível em: http://www.senado.gov.br/sicon.

16. Brasil. Ministério da Fazenda. Sistema de Informações Jurídico-Tributárias [internet]. Brasília, DF: Ministério da Fazenda; 2018 [acesso em 2018 out 12]. Disponível em: http://sijut.fazenda.gov.br/.

17. Banco Nacional de Desenvolvimento Econômico e Social [internet]. Brasília, DF: BNDES; 2018 [acesso em 2018 out 12]. Disponível em: https://www.bndes.gov. br/wps/portal/site/home.

18. Instituto de Pesquisa Econômica Aplicada. Ipeadata [internet]. Brasília, DF: Ipea; 2018 [acesso em 2018 out 12]. Disponível em:http://www.ipeadata.gov.br/Default.aspx

19. Brasil. Agência Nacional de Saúde Suplementar [internet]. Rio de Janeiro: ANS; 2018 [acesso em 2018 out 12]. Disponível em: http://www.ans.gov.br/.

20. Brasil. Banco Central [internet]. Brasília, DF: BCB; 2018 [acesso em 2018 out 12]. Disponível em: https://www. bcb.gov.br/pt-br/\#!/home.

Recebido em 02/08/2018

Aprovado em 19/09/2018

Conflito de interesses: inexistente

Suporte financeiro: não houve 